\title{
LA PRODUCCIÓN INTELECTUAL DEL LICENCIADO EN EDUCACIÓN FÍSICA ENTRE EL PAREDÓN Y LA PALESTRA
}

\section{Nelly T. Martínez*}

\section{Esbozo General del Tema}

El interés central es presentar el trabajo intelectual como producción. En este sentido demostrar a la luz de la teoría organizacional humanista, cómo algunos factores de orden sociocultural relacionados con la satisfacción de las necesidades primarias, aunados al tipo de dirección administrativa que se ejerce en general desde el sistema sociopolítico, y en particular desde el subsistema educativo, o institución donde trabajan los licenciados en Educación Física, conllevan a que la producción intelectual de dicho trabajador no se dé, o sea mínima. Este planteamiento se sustenta por una parte en la experiencia de 17 años como formadora de maestros en Educación Física y en consecuencia conocedora de las características socioeconómicas de los estudiantes de dicha profesión. En segunda instancia, y de manera teórica, en los planteamientos de la escuela behaviorista, en lo tocante a la escala de necesidades humanas, planteadas por A. Maslow, en 1954, y en los estilos de liderazgo, de Mc. Gregor.

Se asume al licenciado como un trabajador y al sistema educativo como la empresa que lo contrata.

Cuando se habla de producción generalmente se asocia con la elaboración de productos materiales, pero rara vez con elaboraciones intelectuales, es decir con la producción de conocimiento, y menos se piensa en el maestro como el trabajador que elabora conocimiento. Esto es válido también para el profesor de Educación Física, pues si se miran las innovaciones pedagógicas, metodológicas o técnicas, no es mucho lo que se encuentra producido por él en cuanto producto material, es decir, escritos. Un recorrido por el mercado lo corrobora: las bibliotecas y librerías no exhiben ni venden textos, libros, periódicos, revistas, etc., elaborados por licenciados de Educación Física colombianos, los pocos que se venden son extranjeros. Pero es que tampoco el área de la Educación Física es considerada aún como campo del conocimiento y de la ciencia, como lo deja ver Colciencias en su libro Convocatoria a la Creatividad al no incluir el deporte entre los programas para el desarrollo de la Ciencia y la Tecnología.

De otra parte la imagen social que tiene la gente (consumidores) de la Educación Física y el deporte, no es precisamente de intelectualidad, al contrario, es de espectáculo, juego, holgazanería, descanso, distracción. Esto es cierto en cuanto a la actividad en sí y más aún en cuanto a sus profesionales o trabajadores, pues maestros, entrenadores, técnicos y demás, no tienen un reconocimiento que los ubique ni socioeconómica ni culturalmente en un nivel alto. Y es que el marco de realidad del desempeño, el licenciado en Educación Física no va más allá de ser una persona que sabe hacer cosas, que enseña a moverse, bailar, jugar, ejecutar, como un operario más. Ocupacionalmente dirige un centro. Tampoco este trabajador se ha destacado mucho como creador. Por lo general se ubica más como subordinado, empleado, sin llegar a ejercer liderazgo como hombre que investiga, que piensa creativamente, que cuestiona o que innova.

\footnotetext{
${ }^{*}$ Profesora del Dpto. de E.F. de la U.P.N. 
El contexto anterior lleva entonces a plantear que la producción intelectual de los licenciados en educación Física es baja. Esto puede explicarse desde tres frentes. Primero, el concepto de intelectualidad en el contexto colombiano (es decir la imagen social del producto). Segundo, el nivel sociocultural de los profesionales o trabajadores de la Educación Física, Deporte y Recreación. Tercero, que el estilo de dirección que reciben desde la administración.

En relación con el primer aspecto, es preciso aclarar que existen muchas concepciones sobre intelectualidad y que ésta va cambiando con el contexto y con el momento histórico, pero que, en esencia, actualmente se entiende por intelectual quien se encarga de forjar visiones nuevas sobre problemas y temas de importancia social y cultural . El que es capaz de corregir la opinión pública y traer de su error a quienes sólo tienen una mirada frente a las cosas, en este caso, frente al deporte, y a la Educación Física. Es intelectual el que se atreve a desenmascarar las relaciones saber y poder, esto es deporte y poder económico. Es un intelectual, aquel que puede hacer de su disciplina el espacio donde la ciencia y la experiencia pueden separarse y situarse recíprocamente, y esto está aún por suceder en el deporte, pues la investigación científica es escasa y aún no se confronta con la experiencia del licenciado.

La división del trabajo atribuye a distintos grupos diversas tareas y funciones, y entre estos se encuentra uno conformado por científicos sociales, ingenieros, médicos, juristas y profesores, quienes están llamados a asumir la función crítica y científica de la sociedad, a tomar conciencia y cuestionar el mundo, es decir, mostrar la verdad. Esta es la función social del maestro, y también del profesor de Educación Física, quien no ha podido aún mostrar sus construcciones intelectuales, a través de la palabra oral ni escrita. No ha podido mostrar al mundo que el Deporte y la Educación Física, como fenómeno de la cultura de la humanidad pueden ser "humanos" y socialmente productivos, no sólo medios de alienación, dependencia, y juego de poderes económicos o espacios propicios para la violencia, la discriminación y el utilitarismo. En otras palabras, la acción intelectual del licenciado en Educación Física no ha llegado aún a tener “...cierta voluntad de saber y relación de poder..." (Foucault, Los Intelectuales y el Saber).

En cuanto al segundo aspecto, el nivel sociocultural o procedencia del licenciado en Educación Física, y que desde otro ángulo también contribuye a reforzar el problema de la baja producción intelectual se puede asegurar que la gran mayoría de los maestros colombianos provienen de las clases medias y bajas, extensivo al maestro de Educación Física, por lo menos al egresado de la Universidad Pedagógica Nacional. Lo he corroborado durante 17 años. Así lo demuestra Rodrigo Parra Sandoval en su libro "Los Maestros Colombianos". Allí puede verse que el $26 \%$ son de clase media alta; el $25 \%$ de media baja y el $49 \%$ son de clase trabajadora.

Desde esta situación, entonces, puede afirmarse que sus intereses laborales se centran, en la satisfacción de las necesidades primarias (Maslow 1954), mientras los otros aspectos como seguridad, asociación, estimación autorrealización, pasan a un segundo plano. Esto lleva a que dicho profesional dirija todo su tiempo, atención y esfuerzo a labores que le den una adecuada remuneración económica en orden a satisfacer las necesidades primarias, es reforzado por el hecho de que dichas labores tienen subvaloración económica (se paga mal) pues desde la mirada social son actividades repetitivas, mecánicas, de poco esfuerzo intelectual. Así termina absorbido en el más bajo nivel de la producción, hacer cosas, sin tiempo ni reconocimiento para desempeñar otra función: producir intelectualmente. 
El tercer aspecto, el tipo de dirección a que se ve sometido no sólo desde el sistema en general, sino desde la organización escolar o institución donde labora, puede decirse que es de tipo autocrático o tradicional (Mac Gregor. en: Aspectos Humanos de la Empresa). Frente a este estilo administrativo, el profesional de la Educación Física tiene que limitar sus posibilidades de hacer producción intelectual porque el director o gerente asume una dirección vertical, donde instruye y hace cumplir las normas y razón social de la empresa, dejando poco espacio para la delegación. Lo que muestra el desconocimiento de los niveles de madurez del licenciado (liderazgo situacional, Hersy y Blanchard) dejado de esta forma, poco o nulo espacio para la iniciativa y creatividad, pues en este tipo de liderazgo existe un control sobre el empleado centrado en tas reglas de la empresa. Todo esto conlleva a hacer del licenciado una persona resignada, mediocre y rutinaria. En situaciones de relación de autoridad como ésta, el ejercicio del maestro se vuelve mecánico, tal como puede verse en la enseñanza de la Educación Física, donde las innovaciones metodológicas o teóricas no se presentan pues no hay cabida para la reflexión, ni la investigación. Hacerlo sería romper con lo establecido en la empresa.

\section{Conclusiones}

Aunque no sea lo usual, la institución escolar, o la de servicios puede mirarse como una empresa; al licenciado que labora en ellas, como un trabajador que cumple unas funciones determinadas por la dirección y en razón de los objetivos establecidos desde todo el sistema y en particular desde el educativo: enseñar a hacer, a jugar, a ejercitarse, o repetir. Estas son las expectativas razonables que se tienen frente al licenciado en Educación Física. Las necesidades de la gente no van más allá de desear placer, sensualidad, gusto. ¿Para qué entonces dicho maestro necesitaría ejercer otro ramo de la producción como sería el intelectual, si la empresa lo que vende son servicios mecanicistas? La producción no requiere un personal (profesor) que se dedique a pensar, a cuestionar, a criticar y menos aún a develar, a través de su pensamiento, el papel alienante que puede ejercer la práctica irracional de la actividad física. En consecuencia, tanto el deporte como la Educación Física continuarán por mucho tiempo estancados en el pragmatismo rutinario y tradicional, si el licenciado no se atreve a plantear la problemática de una Educación Física y un deporte usados con énfasis puramente comercial y de distractor, si no demuestra que sabe hacer otras cosas, como pensar, investigar, para que así pueda ampliar o mejorar el nivel de expectativas frente a su producto: muestre que puede también enseñar a pensar con la Educación Física y por medio de ella. Es el trabajador (licenciado) quien por su capacitación profesional debe retar los sistemas de dirección autoritaria y plantear cosas nuevas, aspirar más allá de lo material, es decir buscar el reconocimiento también como un intelectual que puede ser y tal vez lo sea 